\title{
Retraction Note to: Comparative karyological analysis of three species of Bothriocephalus Rudolphi 1808 (Cestoda:Pseudophyllidea) from Schizothorax species of Kashmir valley
}

\author{
Tanveer A. Sofi ${ }^{1}$ - Fayaz Ahmad
}

Published online: 13 November 2017

(C) Indian Society for Parasitology 2017
Retraction Note to: J Parasit Dis (Jan-Mar 2014) 38(1):16-21
https://doi.org/10.1007/s12639 -012-0185-1

This article (Sofi and Ahmad 2014) has been retracted at the request of the Editor-in-Chief and The Indian Society for Parasitology (ISP) because of overlap with a previously published article by Petkevičiūte (2003). The corresponding author agrees to this retraction.

\section{References}

Petkevičiūte R (2003) Comparative karyological analysis of three species of Bothriocephalus Rudolphi 1808 (Cestoda: Pseudophyllidea). Parasitol Res 89(5):358-363

Sofi TA, Ahmad F (2014) Comparative karyological analysis of three species of Bothriocephalus Rudolphi 1808 (Cestoda: Pseudophyllidea) from Schizothorax species of Kashmir valley. J Parasit Dis 38(1):16-21

The original article can be found online at https://doi.org/10.1007/s12639-012-0185-1.

Tanveer A. Sofi

stanveer96@gmail.com

Fayaz Ahmad

rajafayazali@yahoo.co.in

1 Post Graduate Department of Zoology, University of Kashmir, Srinagar 190 006, Jammu and Kashmir, India 